Vol. 9(10), pp. 307-312, 15 March, 2015

DOI: 10.5897/AJ PP2015. 4289

Artic le Number: EDE73E651656

ISSN 1996-0816

Copyright (c) 2015

Author(s) retain the copyright of this a ricle

African Journal of Pharmacy and

Pharmacology

http://www.academicjoumals.org/AJPP

\title{
The role of nitric oxide in alendronate-mediated acceleration of gastric emptying and gastrointestinal transit in rats
}

\author{
Renan Oliveira Silva ${ }^{1}$, Rudy Diavila Bingana ${ }^{1}$, Pedro Marcos Gomes Soares $^{1}$, Marcellus \\ Henrique Loiola Ponte Souza ${ }^{1}$ and Jand Venes Rolim Medeiros ${ }^{2,3 *}$
}

${ }^{1}$ Department of Physiology and Pharmacology, School of Medicine, Federal University of Ceará, Fortaleza, CE, Brazil.

${ }^{2}$ Biotechnology and Biodiversity Center Research (BIOTEC), Federal University of Piauí, Parnaíba, PI, Brazil.

${ }^{3}$ Post-Graduation Program in Pharmacology, Federal University of Piauí, Teresina-PI, Brazil.

Received 3 February, 2015; Accepted 11 March, 2015

\begin{abstract}
The effect of the alendronate (ALD; $30 \mathrm{mg} / \mathrm{kg}, \mathrm{pH} \mathrm{7.0,} \mathrm{p.o.)} \mathrm{and} \mathrm{sodium} \mathrm{nitroprusside} \mathrm{(SNP;} 10 \mathrm{mg} / \mathrm{kg}$, p.o.; a nitric oxide (NO) donor) on gastric dye retention (GDR) and proximal, medial and distal small intestine dye retentions (IDR) was investigated in rats. The drugs were administered once daily for 4 days. On the last day of treatment, $4 \mathrm{~h}$ after ALD administration, GDR and IDR were measured. ALD treatment decreased GDR at postprandial intervals of $20(28.5 \%)$ and $30 \mathrm{~min}(38.3 \%)$, while it increased medial IDR (117.2\%), as compared to the saline group. ALD had no effect on dye retention in proximal and distal portions of the small intestine. In $30 \mathrm{~min}$, ALD increased medial (50.5\%) and distal IDR (149.7\%), as compared to the saline group. Pretreatment with SNP prevented ALD from decreasing gastric retention and intestinal transit. The results of this study indicated that ALD accelerates gastric emptying of liquids in rats and support the hypothesis that the inhibition of nitric oxide is of primary importance.
\end{abstract}

Key words: Gastric emptying, gaseous mediators, nitric oxide, alendronate.

\section{INTRODUCTION}

Osteoporosis is a disease that is particularly common in elderly patients and is characterized by increased bone brittleness and fracture risk caused by low bone mineral density (BMD) and degeneration of the bone microarchitecture (Silva, 2003; Brandão et al., 2008). Various drugs are available for the treatment and prevention of osteoporosis. The beneficial effects of bisphosphonates such as alendronate (ALD) on calcium metabolism are well established, and today, they are the major class of drugs used to treat bone diseases associated with excessive resorption. However, these drugs cause serious adverse effects including bleeding, inflammation, and abdominal pain and can through an unknown mechanism, cause additional side effects in the

*C orresponding author. E-mail: jandvenes@ufpi.edu.br.

Author(s) agree that this article remain pemanently open access und er the terms of the Creative CommonsAttribution License 4.0 Intemational License 
upper gastrointestinal tract, including gastroesophageal inflammation and ulceration (Marshall et al., 2000; Graham, 2002).

Nitric oxide (NO) is a major inhibitory neurotransmitter in the gastrointestinal tract, and appears to mediate enteric smooth muscle relaxation (Takahashi, 2003). In healthy subjects, an increase in NO availability has been reported to slow gastric emptying. Exogenous nitric oxide inhibits gastric emptying and antral motor activity (Plourde et al., 1994; Konturek et al., 1995), and the nitric oxide synthase inhibitor, $L-N^{G}$-nitroarginine methyl ester (L-NAME), attenuates the delay in gastric emptying (Kuo et al., 2009). Recently, we demonstrated that ALDinduced gastric ulcerogenic responses were mediated by a decrease in NO derived from both endothelial nitric oxide synthase (eNOS) and inducible nitric oxide synthase (iNOS) (Silva et al., 2014).

However, there are few reports concerning the effects of ALD on gastrointestinal motility in vivo, and there have been no investigations into its effect on nitrergic mechanisms. As a result, we investigated the effect of ALD on the gastric emptying of liquid meals in rats and evaluated the involvement of NO with this phenomenon.

\section{MATERIALS AND METHODS}

\section{Animals}

Female Wistar rats (100 to $150 \mathrm{~g}$ ) were obtained from the Department of Physiology and Pharmacology, Federal University of Ceará and housed in cages with a controlled temperature (25 \pm $2^{\circ} \mathrm{C}$ ) and a 12-h light/12-h dark cycle. The animals were deprived of food for 18 to $24 \mathrm{~h}$ before the experiment, but had free access to water. All animal treatments and surgical procedures were performed in accordance with the Guide for Care and Use of Laboratory Animals (National Institutes of Health, Bethesda, MD, USA) and were approved by the local Ethics Committee (Protocol No. 0067/10).

\section{Drugs}

Alendronate (ALD) and sodium nitroprusside (SNP) were purchased from Sigma Aldrich (St. Louis, MO, USA). ALD was dissolved in saline and adjusted to $\mathrm{pH} 7.0$ using $\mathrm{NaOH}$ or $\mathrm{HCl}$ (Kanatsu et al., 2004). All other drugs were dissolved in saline $(0.9 \% \mathrm{NaCl})$.

\section{Experimental protocol}

The animals were divided randomly in four groups ( $n=6$ to 7 animals): Group I, Saline; Group II, SNP (10 mg/kg, p.o.); Group III, ALD (30 mg/kg, pH 7.0, p.o.); and Group IV, SNP (10 mg/kg, p.o.) + ALD $(30 \mathrm{mg} / \mathrm{kg}$ ). The drugs were administered once daily for 4 days, and doses were chosen based on the results from previous work conducted by our research group (Silva et al., 2014). On the last day of treatment, $4 \mathrm{~h}$ after saline or ALD administration (Groups I to IV), gastric emptying and intestinal transit were measured as described subsequently.

\section{Evaluation of gastric emptying and intestinal transit}

Gastric emptying and intestinal transit were performed according to a method described previously (Reynell and Spray, 1956), with modifications. Initially, the animals received phenol red $(1.5 \mathrm{ml} ; 0.75$ $\mathrm{mg} / \mathrm{ml}$ in $5 \%$ glucose). After 10,20 , or $30 \mathrm{~min}$, animals were euthanized, a laparotomy was performed, and the gastroesophageal, gastroduodenal, and ileocaecal junctions were immediately isolated by ligatures, removed and divided into consecutive segments: stomach, proximal (40\%), middle (30\%), and distal (30\%) small intestine. Then, each segment was placed in a graduated cylinder that contained $0.1 \mathrm{~N} \mathrm{NaOH}(100 \mathrm{ml})$ solution and total volume was measured. After $20 \mathrm{~min}$, the supernatant (10 $\mathrm{ml}$ ) was collected and centrifuged at $2800 \mathrm{rpm}$ for $10 \mathrm{~min}$. Subsequently, $20 \%$ trichloroacetic acid (TCA; $0.5 \mathrm{ml}$ ) was added to the homogenate $(5 \mathrm{ml})$ for protein precipitation and centrifuged at 2800 for $20 \mathrm{~min}$. Finally, samples of supernatant $(150 \mu \mathrm{l})$ were added to $200 \mu \mathrm{l}$ of $\mathrm{NaOH}(0.5 \mathrm{~N}$ in distillated water) and the absorbance was measured on a plate reader at $560 \mathrm{~nm}$. The results are expressed as fractional dye retention (\%), according to the following equation:

Gastric dye retention $=\frac{\text { Phenol red recovered in stomach }}{\text { Phenol red recovered from stomach and intestine }} \times 100$

Intestinal transit was calculated for gut bowel segments by dividing the amount of phenol red recovered from a given segment by the amount of phenol red recovered from all three segments, and it is expressed as fractional dye retention (\%) (Peixoto-Junior et al., 2009).

\section{Role of NO in ALD-enhanced gastric emptying of liquid}

To study the role of NO in the effect of ALD on gastric emptying, rats were pretreated with saline or SNP (10 $\mathrm{mg} / \mathrm{kg}$, p.o.; a nitric oxide donor). After $1 \mathrm{~h}$, animals received ALD (30 mg/kg, p.o.). The drugs were administered once daily for 4 days. On the last day of treatment, $4 \mathrm{~h}$ after saline or ALD, the rats received phenol red $(1.5 \mathrm{ml} ; 0.75 \mathrm{mg} / \mathrm{ml}$ in $5 \%$ glucose). After 20 min, animals were sacrificed and gastric retention was measured as previously described.

\section{Statistical analysis}

All values are expressed as means \pm standard error of mean (S.E.M). The analysis of variance (ANOVA) and Student-Newman-Keuls test were used to determine the statistical significance of differences between groups. Differences were considered as significant at $p<0.05$.

\section{RESULTS}

\section{Evaluation of gastric emptying at postprandial intervals}

Figure 1 shows that ALD significantly $(p<0.05)$ decreased gastric retention at postprandial intervals of 20 


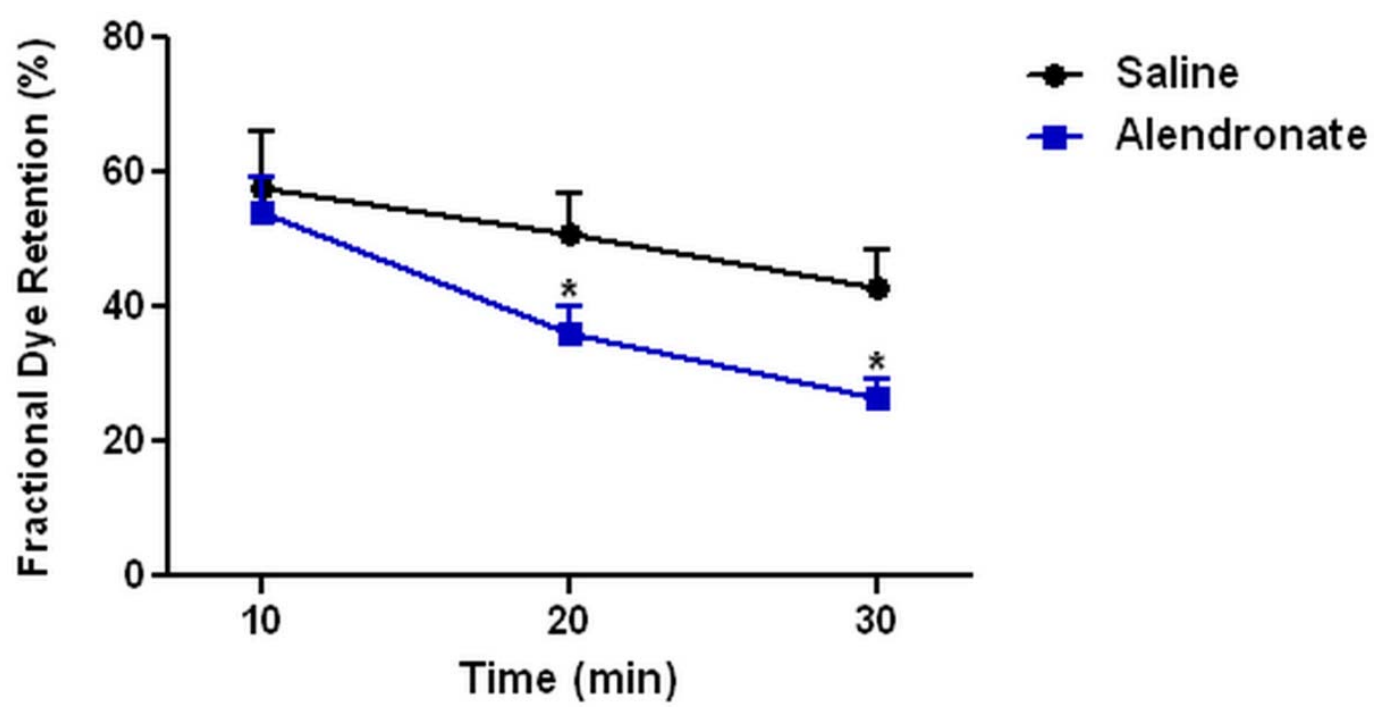

Figure 1. Alendronate treatment accelerates gastric emptying in rats. Rats received saline (control group) or alendronate (30 mg/kg, p.o.) once daily for 4 days. On the last day of treatment, $4 \mathrm{~h}$ after administration, the animals received phenol red $(1.5 \mathrm{ml} ; 0.75 \mathrm{mg} / \mathrm{ml})$ and were sacrificed 10, 20 or 30 min later. Values are expressed as mean \pm SEM ( $n=6$ to 7 rats per group). ${ }^{*} p<0.05$ versus saline group.

$\min (36.24 \pm 3.76$ versus $50.69 \pm 6.24 \% ; 28.5 \%$ of reduction) and $30 \mathrm{~min}(26.47 \pm 2.73$ versus $48.88 \pm$ $5.57 \% ; 38.3 \%$ of reduction), as compared to the saline group.

\section{Effect of alendronate on gastric emptying and intestinal transit}

Figure 2 shows the gastric dye retention (GDR) and proximal, medial, and distal small intestine dye retentions (IDR) in saline- or ALD-treated animals 10,20 , and 30 min after gavage. In Figure $2 \mathrm{~A}$, the fractional dye retention $10 \mathrm{~min}$ after receiving the test meal in ALDtreated animals, did not change in stomach and any portion of the small intestine. However, ALD treatment significantly $(p<0.05)$ decreased GDR $(36.24 \pm 3.76$ versus $50.69 \pm 6.24 \%$; $28.5 \%$ of reduction) while it significantly $(p<0.05)$ increased medial IDR $(18.37 \pm$ 4.16 versus $39.91 \pm 3.65 \%$ fractional dye retention; $117.2 \%$ of increase) 20 min after receiving the test meal (Figure 2B). ALD had no effect on dye retention in proximal and distal portions of the small intestine in this time.

Figure $2 \mathrm{C}$ shows the fractional dye retention in salineor ALD-treated animals $30 \mathrm{~min}$ after receiving the test meal. Compared to the saline group, ALD treatment significantly $(p<0.05)$ decreased GDR $(48.88 \pm 5.57$ versus $26.47 \pm 2.73 \%$; $38.3 \%$ of reduction) while increased medial $(29.21 \pm 3.62$ versus $43.80 \pm 4.52 \%$; $50.5 \%$ of increase) and distal IDR (5.62 \pm 0.78 versus $14.06 \pm 2.83 \% ; 149.7 \%$ of increase). ALD had no effect on dye retention in the proximal portion of the small intestine.

\section{Role of NO in the effect of alendronate on gastric emptying and intestinal transit}

Figure 3 show that SNP (a nitric oxide donor) pretreatment significantly $(p<0.05)$ prevented decreasing GDR (52.65 \pm 2.96 versus $36.24 \pm 3.76 \%$ fractional dye retention) medial IDR $(21.80 \pm 3.19$ versus $39.913 .64 \%$ fractional dye retention) altered by ALD administration.

As shown in Figure 4, it was observed that the marker progressed through the intestine; the center of mass advanced gradually over $20 \mathrm{~min}$ after the meal, that intestinal transit was significantly $(p<0.05)$ improved in the ALD group, as compared to the saline group (median geometric center: $2.09 \pm 0.04$ versus $1.67 \pm 0.15$ ), but was normalized by SNP pretreatment $(1.78 \pm 0.06)$. In addition, the treatment only with SNP did not alter this parameter.

\section{DISCUSSION}

ALD is an aminobisphosphonate, potent inhibitor of osteoclast-mediated bone resorption, which is marketed for the treatment of osteoporosis and Paget's disease of bone (Liberman et al., 1995). Unfortunately, these drugs are also capable of causing injury to the upper gastrointestinal tract, causing gastric injury and delays ulcer healing in rodents (Elliott et al., 1998). In patients, gastrointestinal adverse events reported during ALD 

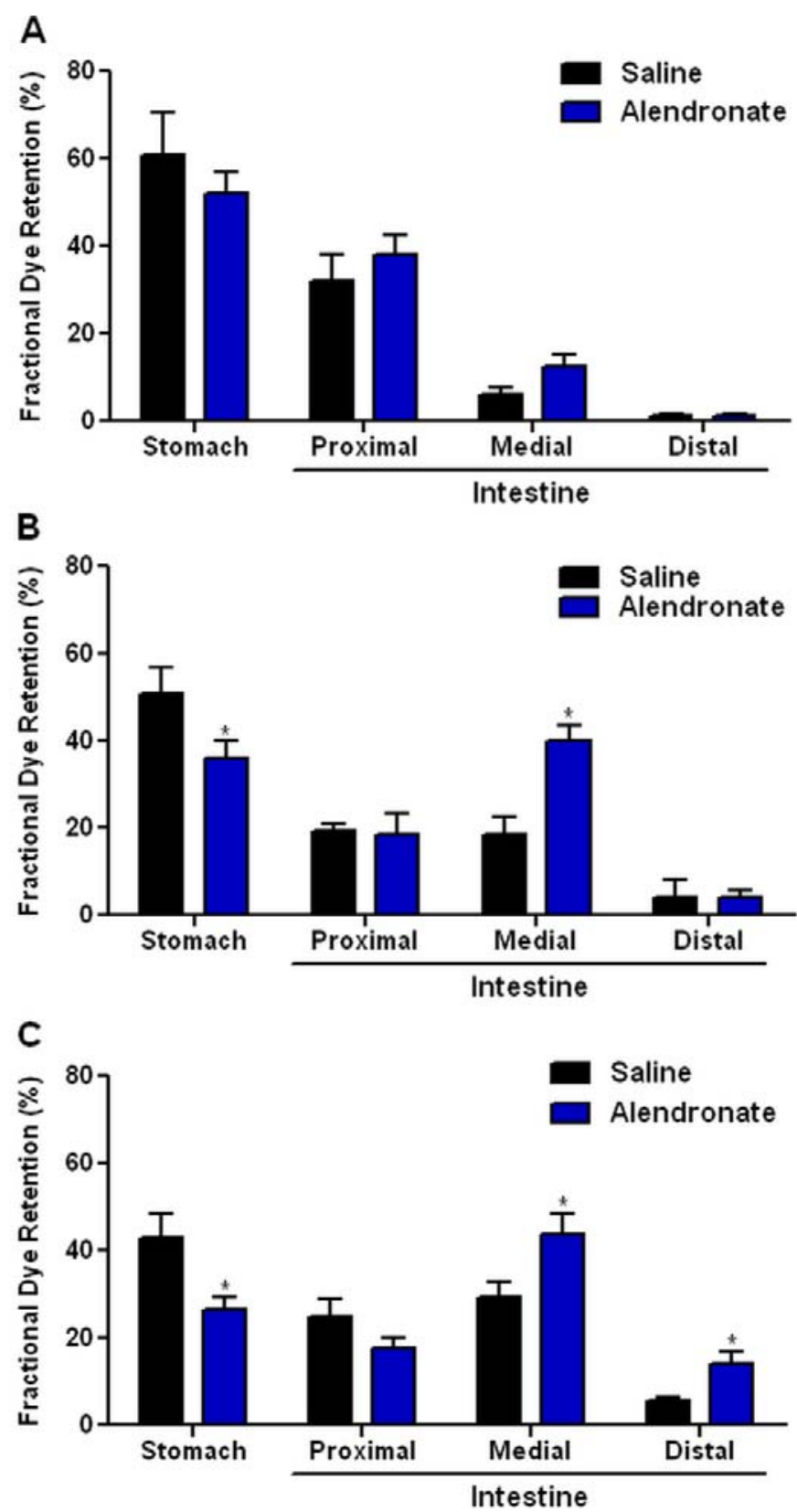

Figure 2. Alendronate treatment accelerates gastric emptying and gastrointestinal transit in rats. Rats received saline (control group) or alendronate (30 mg/kg, p.o.) once daily for 4 days. On the last day of treatment, $4 \mathrm{~h}$ after administration, the animals received phenol red $(1.5 \mathrm{ml} ; 0.75 \mathrm{mg} / \mathrm{ml})$ and were sacrificed 20 min later. Values are expressed as mean \pm SEM ( $n=6-7$ rats per group). ${ }^{*} p<$ 0.05 versus saline

therapy also include dyspepsia, dysphagia, and oesophageal ulcers (Thomson et al., 2002). Another side effect seen in patients with the use of alendronate is complications of gastrointestinal transit. However, there are few studies linking alendronate with these effects and the mechanism involved. Thus, in this work, we evaluated the effect of ALD on the gastric emptying (GE) and gastrointestinal transit $(\mathrm{Gl})$ of liquid in rats. We also investigated the role of NO in this process.

Analysis of fractional dye retention has been widely used to assess gastric emptying (Medeiros et al., 2012; Gondim et al., 2001; Sharma, 1983). It allowed us to evaluate gastric and intestinal motility in rodents, thus eliminating the need for anesthesia and its associated effects on the cardiovascular and autonomic functions; as a result, our model closely mimicked the clinical scenario. Our results showed that ALD accelerates the GE and GI of liquids in rats. Therefore we can infer that ALD has prokinetic effects on gastric motility.

There are few reports concerning the effects of ALD on gastrointestinal motility in vivo. We are one of the first groups to report that ALD can accelerate the GE and GI of liquids in rats. This effect could be due to a decrease in nitric oxide synthesis, since we demonstrated that the nitrergic donor SNP inhibits the effect of ALD on gastrointestinal motility. It, is evident from the literature that NO and nitrergic donors inhibit gastrointestinal motility, both in animals and humans (Sun et al., 1998; Allescher et al., 1992).

Additionally, it was demonstrated that ALD reduced NO generation by modulating NOS expression (Silva et al., 2014). The three enzymatic sources of NO-nNOS, eNOS, and iNOS, have been shown to exist in the gastrointestinal tract. Several studies have demonstrated that NO plays a dual role in the mucosal protection and $\mathrm{GI}$ motility depending on the NOS isoform involved; the protective effect of NO is derived from nNOS and eNOS, and the inhibition of these enzymes can accelerate $\mathrm{GI}$ motility and induce disturbances in blood flow, secretion, and gastric ulcers. In contrast, iNOS, which generates large amounts of NO under certain pathological conditions, is thought to contribute to mucosal injury and dysfunction (Moncada et al., 1991). Since the administration of alendronate diminishes NO levels in the gastric mucosa (Silva et al., 2014), it is believed that this effect contributes to the prokinetic effects of ALD, and increase in NO levels by SPN abolished the ALD effects in $\mathrm{GE}$ and $\mathrm{Gl}$.

\section{Conclusion}

Conclusively, our results indicate that ALD accelerates gastric emptying of liquids in rats. Although there are many mechanisms by which this effect could occur; our data support the hypothesis that the inhibition of nitric oxide is of primary importance.

\section{Conflict of interests}

The authors declare that there is no conflict of interests.

\section{ACKNOWLEDGEMENTS}

The authors gratefully acknowledged the financial 


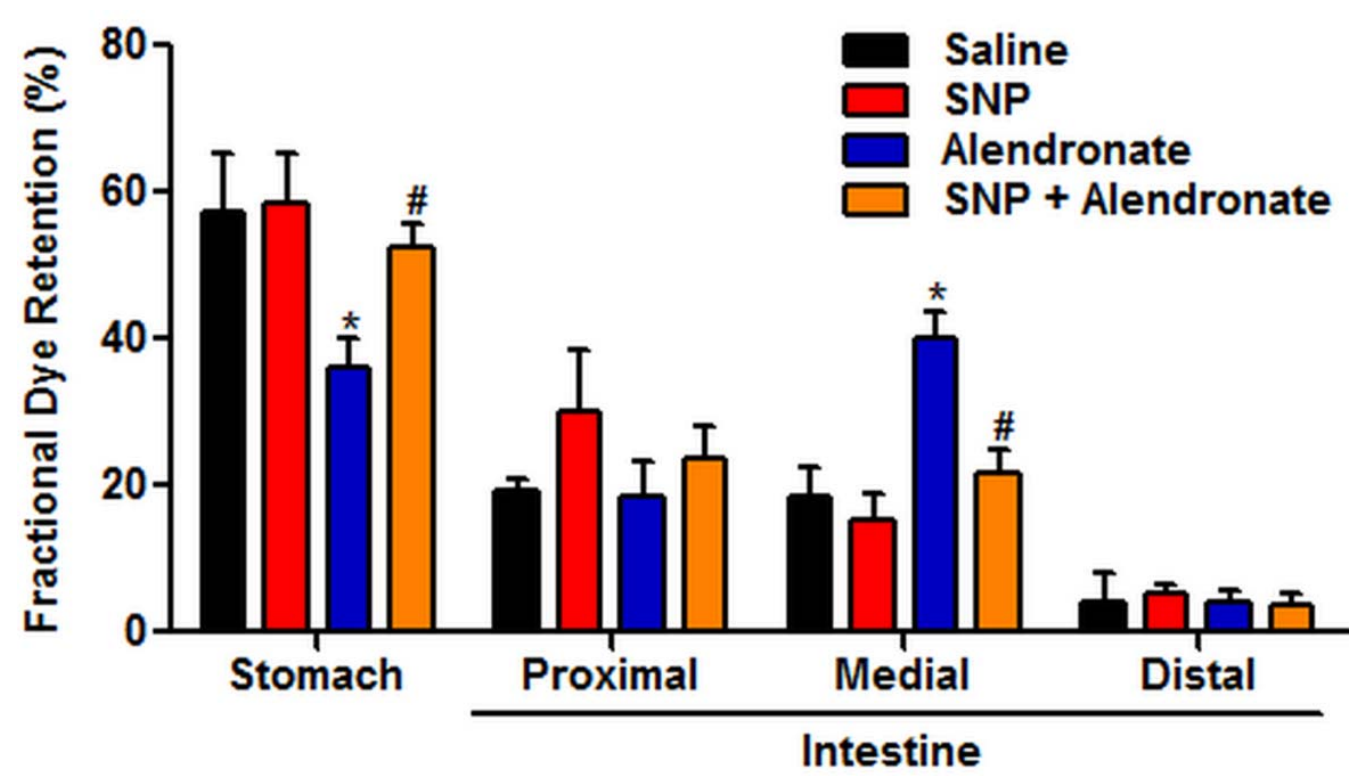

Figure 3. Sodium nitroprusside treatment reverses the effects of alendronate on gastric emptying and gastrointestinal transit. Rats were treated with either saline (control group) or SNP (10 mg/kg, p.o.; a nitric oxide donor) $30 \mathrm{~min}$ before alendronate (30 mg/kg, p.o.) administration. All drugs were administered once daily for 4 days. On the last day of treatment, $4 \mathrm{~h}$ after saline or alendronate administration, the animals received phenol red $(1.5 \mathrm{ml} ; 0.75 \mathrm{mg} / \mathrm{ml})$ and were sacrificed $20 \mathrm{~min}$ later. Values are expressed as mean \pm SEM ( $n=6-7$ rats per group). ${ }^{\star} p<0.05$ versus saline group; ${ }^{*} p<0.05$ versus alendronate group.

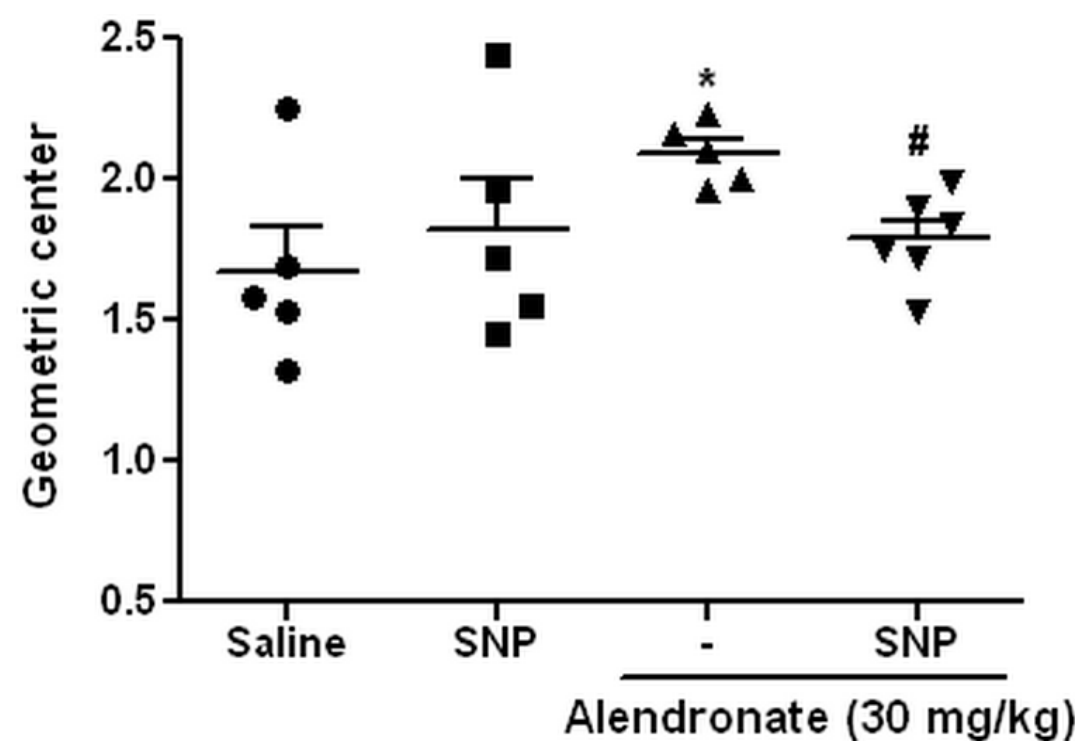

Figure 4. Sodium nitroprusside treatment prevents the detachment of the geometric center of the distribution the test meal induced by alendronate. Rats received saline (control group) or SNP (10 mg/kg, p.o.; a nitric oxide donor) $30 \mathrm{~min}$ before alendronate (30 mg/kg, p.o.) administration. All drugs were administered once daily for 4 days. On the last day of treatment, $4 \mathrm{~h}$ after administration, the animals received phenol red $(1.5 \mathrm{ml} ; 0.75 \mathrm{mg} / \mathrm{ml})$ and were sacrificed 20 min later. Values are expressed as mean \pm SEM ( $n=5-6$ rats per group). ${ }^{*} p<0.05$ versus saline group; ${ }^{*} p<0.05$ versus alendronate group. 


\section{Research Foundation for the State of Piauí - FAPEPI.}

\section{REFERENCES}

Allescher HD, Tougas G, Vergara P, Lu S, Daniel EE (1992). Nitric oxide as a putative nonadrenergic noncholinergic inhibitory transmitter in the canine pylorus in vivo. Am. J. Physiol. 262:695702.

Brandão CMR, Lima MG, Silva AL, Silva GD, Guerra Jr. AA, Acúrcio FA (2008). Treatment of postmenopausal osteoporosis in women: a systematic review. Cad. Saúde Pública 24:592-606.

Elliott SN, Mcnight W, Davies NM, MacNaughton WK, Wallace JL (1998). Alendronate induces gastric injury and delays ulcer healing in rodents. Life Sci. 62:77-91.

Gondim FA, Rodrigues CL, Graca JR, Camurça FD, de Alencar HM, dos Santos AA, Rola FH (2001). Neural mechanisms involved in the delay of gastric emptying and gastrointestinal transit of liquid after thoracic spinal cord transection in awake rats. Auton. Neurosci. 87:52-58.

Graham DY (2002). What the gastroenterologist should know about the gastrointestinal safety profiles of bisphosphonates. Dig. Dis. Sci. 47:1665-1678.

Kanatsu K, Aihara E, Okayama M, Kato S, Takeuchi K (2004). Mucosal irritative and healing impairment action of risedronate in rat stomachs: comparison with alendronate. J. Gastroenterol. Hepatol. 19:512-520.

Konturek JW, Thor P, Domschke W (1995). Effects of nitric oxide on antral motility and gastric emptying in humans. Eur. J. Gastroenterol. Hepatol. 7:97-102.

Kuo P, Gentilcore D, Nair N, Stevens JE, Wishart JM, Lange K, Gilja $\mathrm{OH}$, Hausken T, Horowitz M, Jones KL, Rayner CK (2009). The nitric oxide synthase inhibitor, Ng-nitro-L-argininemethyl-ester, attenuates the delay in gastric emptying induced by hyperglycaemia in healthy humans. Neurogastroenterol. Motil. 21:1175-1183.

Liberman UA, We iss SA, Broll J, Minne HW, Quan $\mathrm{H}$, Bell $\mathrm{NH}$, Rodrigue z-Portales J, Downs RW, Deque ker J, Farus M, Seeman E, Recker RR, Capizi T, Santora AC, Lombardi A, Shaw R, Hirsch LJ, Karpf DB (1995). Effect of oral alendronate on bone mineral density and the incidence of fractures in postmenopausal osteoporosis. N. Engl. J. Med. 333:1437-1443.

Marshall JK, Rainsford KD, James C, Hunt RH (2000). A randomized controlled trial to assess alendronate-associated injury of the upper gastrointestinal tract. Aliment. Pharmacol. Ther. 14:1451-1457.
Medeiros JVR, Bezerra VH, Lucetti LT, Lima-Júnior RCP, Barbosa ALR, Tavares BM, Magalhães PJC, Santos AA, Cunha FQ, Soares PMG, Souza MHLP (2012). Role of KATP channels and TRPV1 receptors in hydrogen sulfide-enhanced gastric emptying of liquid in awake mice. Eur. J. Pharmacol. 693:57-63.

Moncada S, Palmer RMJ, Higgs EA (1991). Nitric oxide: physiology, pathology and pharmacology. Pharmacol. Rev. 43:109-142.

Peixoto-Junior AA, Teles BCV, Castro EFB, Santos AA, Oliveira GR, Ribeiro RA, Rola FH, Gondim FA (2009). Vincristine delays gastric emptying and gastro intestinal transit of liquids in awake rats. Braz. J. Med. Biol. Res. 42:567-573.

Plourde V, Quintero E, Suto G, Coimbra C, Tach Y (1994). Delayed gastric emptying induced by inhibitors of nitric oxide synthase in rats. Eur. J. Pharmacol. 256:125-129.

Reynell PC, Spray GH (1956). A technique for the simultaneous measurement of absorption and transit in the gastro-intestinal tract of the rat. J. Physiol. 131:452-462.

Sharma RK (1983). Study of gastric \& intestinal motility in young \& adult rats. Indian J. Med. Res. 78:713-723.

Silva LK (2003). Avaliação tecnológica em saúde: densitometria óssea e terapêuticas alternativas na osteoporose pós-menopausa. Cad. Saúde Pública 19:987-1003.

Silva RO, Lucetti LT, Wongb DVT, Aragao KS, A. Junior EM, Soares PMG, Barbosa ALR, Ribeiro RA, Souza MHLP, Medeiros JVR (2014). Alendronate induces gastric damage by reducing nitric oxide synthase expression and NO/cGMP/KATP signaling pathway. Nitric Oxide 40:22-30.

Sun WM, Doran S, Jones KL, Ooi E, Boeckxstaens G, Hebbard GS, Lingenfelser T, Morley JE, Dent J, Horowitz M (1998). Effects of nytroglicerin on liquid gastric emptying and antropyloroduodenal motility. Am. J. Physiol. 275:1173-1178.

Takahashi T (2003). Pathophysiological significance of neuronal nitric oxide synthase in the gastrointestinal tract. J. Gastroenterol. 38:421430.

Thomson AB, Marshall, JK, Hunt RH, Provenza JM, Lanza FL, Royer MG, Li Z, Blank, MA (2002). Risedronate Endoscopy Study Group: 14 Day endoscopy study comparing risedronate and alendronate in postmenopausal women stratified by Helicobacter pylori status. J. Rheumatol. 29:1965-1974. 